MATEC Web of Conferences 36, 03002 (2015)

DOI: $10.1051 /$ matecconf/ 20153603002

(C) Owned by the authors, published by EDP Sciences, 2015

\title{
Analysis of micro-particles vacuumed from the Turin Shroud
}

\author{
Irene Calliari ${ }^{1}$, Caterina Canovaro ${ }^{2}$ \\ ${ }^{1}$ Department of Industrial Engineering, University of Padua, Italy, irene.calliari@unipd.it \\ ${ }^{2}$ Department of Geological Science, University of Padua, Italy
}

\begin{abstract}
The results of some Turin Shroud particles (3 to $30 \mu \mathrm{m}$ ) examination are presented. A research was performed with the aim to classify the particles in order to correlate them with the environments where, from historical information, the Shroud resulted to have been exposed. Grains of pollen, flax and cotton fibers, mites, spores and fungi, mineral particles and particles related to body fluids were detected and classified. Attention has been focalized to the pollen grains, to discuss M. Frei's results, without forgetting a more general investigation aimed at evidencing new information for the Shroud studies. A few cotton fiber were found to be mixed with flax ones. Moreover, many mineral particles are compatible with the Jerusalem soil.
\end{abstract}

\section{Introduction}

In 2009-2011 the Research Project on "Multidisciplinary analysis applied to the Turin Shroud: study of the body image, of possible ambient pollution and of micro-particles capable to characterize the flax fabric" has been performed at the University of Padua.

The main points of the project were the following ones.

-1) Analysis of the formation mechanism of the body image with formulation of the most reliable hypothesis.

Different hypothesis for the body image formation have been formulated [1-4], but none of them satisfies the very special features of the TS image. The hypothesis based on radiation, thermal and ultraviolet rays have been considered and they have been opportunely verified with experimental tests in Ref. [4].

Basing on quantitative results of image analysis, a directional radiation proportional to the body-cloth distance has been considered as the most probable cause of image formation. Experimental results have been studied both from a macroscopic point of view comparing them with the ones typical of the TS image, and from a microscopic point of view. The best hypothesis of body image formation appears the one based on Corona Discharge [5].

-2) Analysis of the possible causes of pollution of the TS samples taken in 1988, for radiocarbon dating purposes.

In 1988 a sample of fabric of the TS was taken from a corner and it was radiocarbon dated using the AMS technique. The result, published in Nature [6] provided a dating between 1260 and 1390 with a confidence level of $95 \%$. That dating appears questionable [7] because of some statistical erroneous details reported in the same article, and due to the presence of a trend possibly caused by environmental factors. This conclusion has been reached with the help of robust statistics [7] that suggests the presence of a contamination in the sample. 
The present analysis is also addressed to determine the possible causes of contamination. Fire, water, carbon monoxide, dirty and other pollutants, also caused by some kind of radiation, have been experimentally tested making AMS analyses on reference samples, but at the moment it seems that only a neutron radiation could be the responsible of the detected systematic effect.

-3) Analysis of the morphological features of the flax fibers contained in the TS.

The morphological features of the TS flax fibers have been compared with other flax fibers coming both from recent fabrics and from Egyptian and Israeli ancient fabrics. This comparison evidenced some difference related to the retting process. Such morphological features can be better highlighted when flax fibers are observed through a petrographic microscope in crossed polarized light at magnifications of $100 x-600 x$. The analysis in polarized light highlights features of different types such as changes of thickness which cause chromatic changes and structural defects.

The analysis in cross-polarized light of the so-called "kink bands" (circumferential defects of flax fibers, consisting in folding of the primary fiber layer), typical of the flax fibers, showed interesting results in reference to the TS-image-fibers. It resulted that the chemical process that produced color also caused a remarkable increase of "kink bands" thus showing a structural change of the colored flax fiber.

From the mechanical point of view, an opportune equipment able to measure the tensile strength of single flax fibers has been built and at present interesting results also regarding TS fibers are under analysis.

-4) Analyses of microparticles present in the TS.

The various micro-particles of vegetable and mineral origin, having a diameter of about 3-30 $\mu \mathrm{m}$, (with pollen particles), are the object of the analysis that is widely discussed in the present work.

The initial aim was to perform a classification of these particles and, if possible, to refer it to the environments where, from historical information, possibly TS was exposed.

The analysis has been focalized to verify the presence of pollen typical of flora living in zones described by the probable historical journey of the TS. This study has also been performed to verify some statements reported in previous papers [8-10] that suppose a particular historical journey of the TS in the first centuries, based on the pollen identification.

-5) Analysis of the body fluids particles.

Probably, among the various micro-particles, there are mixed with some derived from the discharge of body fluids such as blood serum. Some scientists [11,12] have already identified various items from the TS as particles coming from human body fluids.

The present study is also addressed to try to classify the biological material of human origin, also trying to determine their chemical composition.

Starting from a previous study [13], the present work is aimed at analyzing the characteristic dusts aspired from the TS by focalizing the attention on the pollen grains, but in general to evaluate which kind of information could be obtained.

\section{Methods and Samples}

In 1978 and in 1988 some dusts were vacuumed [14] from the back of the TS and sampled in various filters. Some statistical analyses have been done on these dusts [13], and other analyses were performed principally for conservation problems $[15,16]$.

The sampled dusts were vacuumed from space between the TS and the Holland Cloth, in filters named from "e" to "i" in reference to the vacuuming area shown in Ref. [14]. The dusts, object of the present study, come from very small parts taken from filters "e", "f", "g", "h" and "i" and sampled in stubs suited for SEM (Scanning Electron Microscope) analysis.

A dozen of stubs were used and each stub has been classified with the first letter corresponding to the name of the filters "e" to "i". A proper adhesive was put on the aluminium stubs and some micrograms of dust were placed on the adhesive. Before the analysis, the samples were metallized with gold, and the corresponding peaks can be observed in the spectra. 
Before to metallize the samples, a series of photomicrographs were obtained using an optical microscope in incident light in order to maintain the color information that is successively destroyed with metallization; Fig. 1 shows an example.

To register the position of the single particles in the stub under analysis, an area of interest was previously defined and this area has been mapped by acquisition of a number of images needed to generate a photo-mosaic. A reasonable step between successive shots was reserved in such a way to ensure their partial overlap, which is necessary for the mosaic.

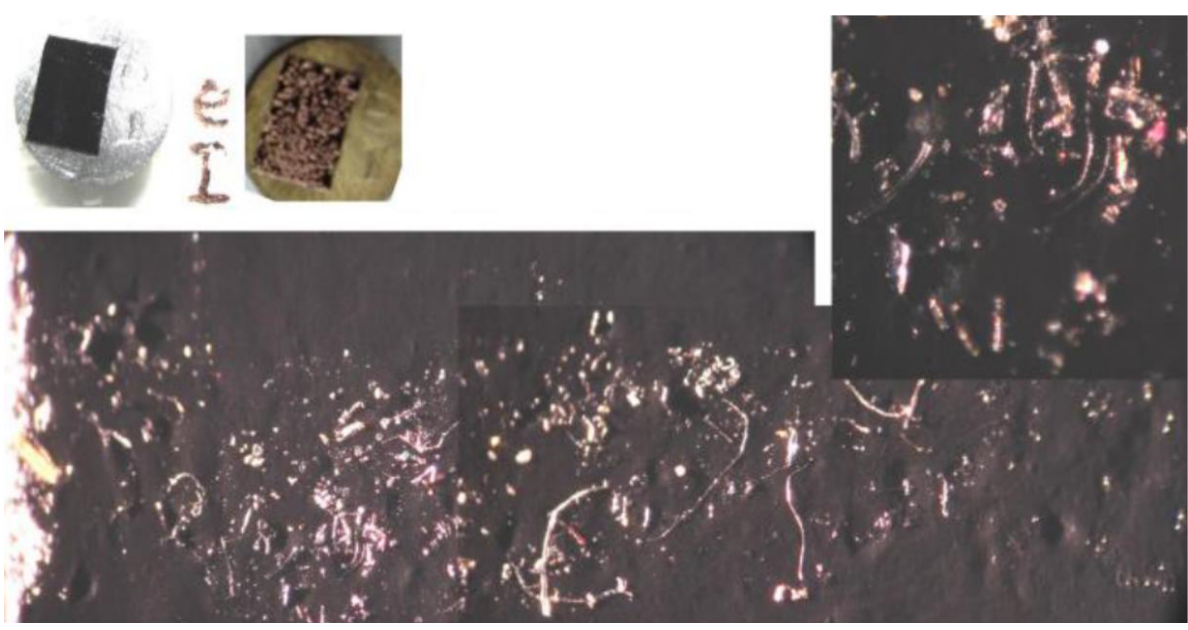

Figure 1. Example of map obtained using an optical microscope on Stub EI in order to save the colour information relative to the dust samples.

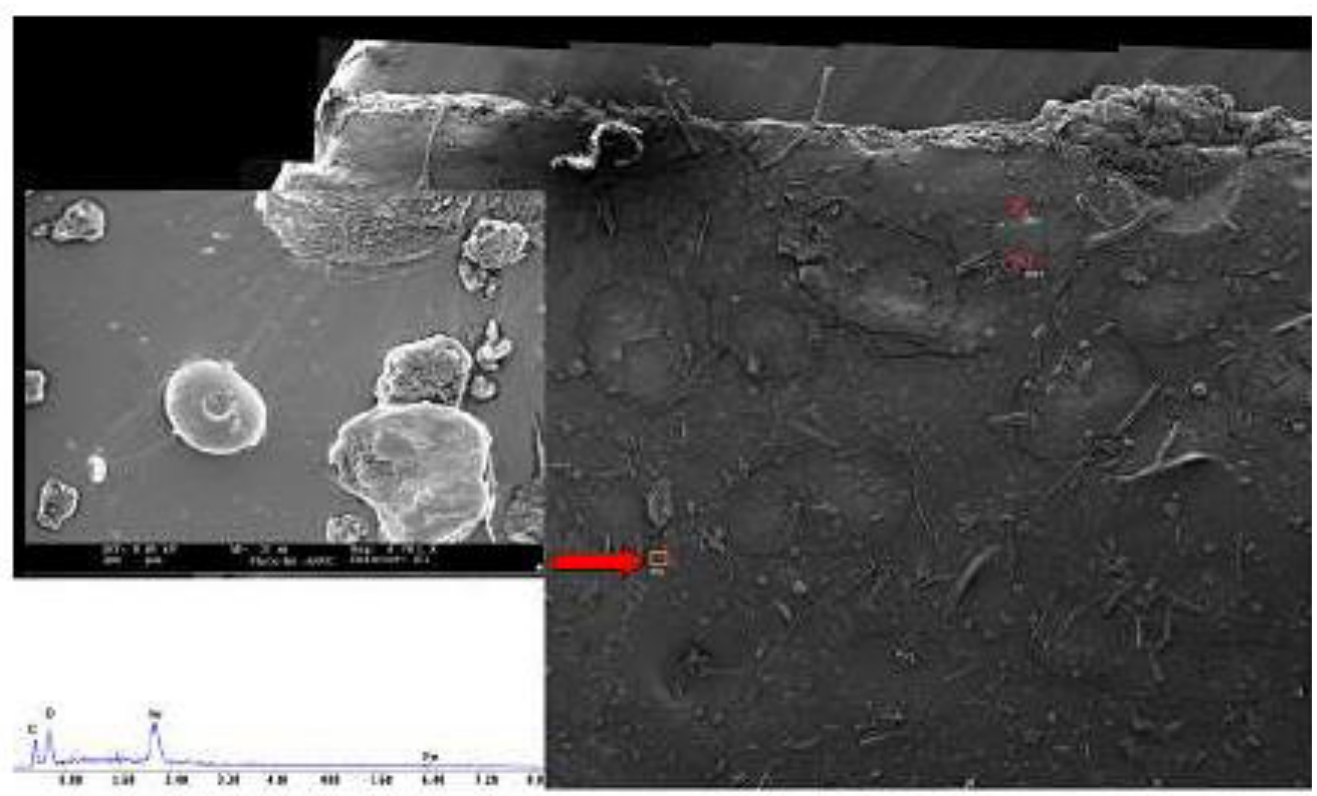

Figure 2. Example of map obtained from Stub EC (on the right) and a detail of an organic particle (on the left) with the corresponding position on the map evidenced by the arrow. The EDS spectra indicate that there are atoms of carbon $(\mathrm{C})$ and oxygen $(\mathrm{O})$ in addition to the gold $(\mathrm{Au})$ due to the metallization thus showing that the particle under analysis is of organic type. 
The analysis of spores, pollen and mineral particles has been obtained on dust particles ranging from 3 to $30 \mu \mathrm{m}$ both by morphological investigation at high magnifications (5000-7000 X), and through the acquisition of the relative spectra (EDS) in order to have additional information of the chemical composition of the particle. It has been possible therefore to assess the organic origin of the particles and their elemental composition.

For example the map relative to stub EI (fig. 2) is the result of the photo-collage of 50 photos at magnification of $650 x$; it shows the map and a detail with the corresponding spectrum.

\section{Results and Discussion}

Different categories of particles have been recognized: pollen; flax and cotton fibers; mites, spores and fungi; mineral particles; particles possibly coming from body fluids. Below they are considered separately.

\subsection{Pollen}

During the analysis, some particles were associated, by size, to pollen grain, which, however, were not simple to identify due to surface alterations. In the Stub $\mathrm{HH}$ a grain identified as pollen grain of Phillyrea Angustifolia, has been observed (fig. 3) in agreement with previous studies [8-10] where M. Frei's reported some SEM micrographs of 48 varieties of pollen. Among those SEM photos there is one of the same Phillyrea Angustifolia [9].

This pollen grain in the TS dusts confirms the seriousness of M. Frei and partially explains why the palynologist preferred to show photo reproducing a better conserved grain. The pollen grain shown in Fig. 3 and probably also the others observed by M. Frei were not perfect because they were very old, and therefore a perfect grain was preferred to show the corresponding features.

The Phillyrea Angustifolia is a woody plant blooming in March-May with a bushy or small tree evergreen that can reach a height of 2-4 meters; it is typical of the Mediterranean Scrub and is not very demanding as it is particularly suited to cultivation in drought soils and grows in areas especially on the coasts.

Fig. 4 shows a pollen grain ascribable to the family of Liliacées, perhaps of Fraxinus angustifolia. Fig. 5 shows a pollen grain not easy to classify.

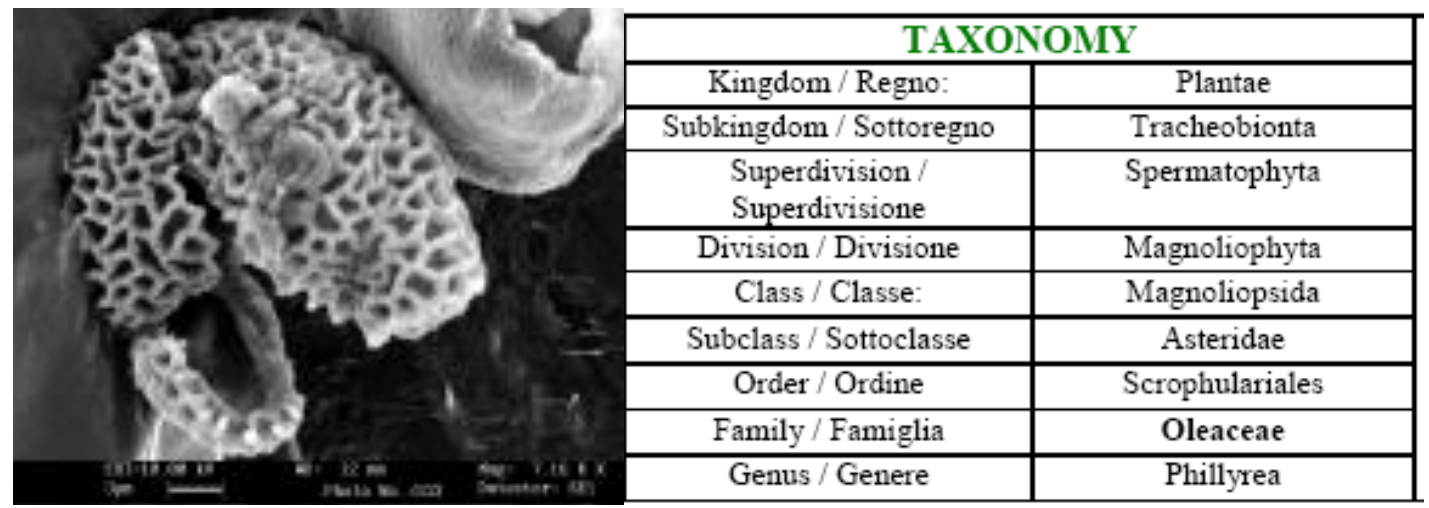

Figure 3. Pollen grain of Phillyrea Angustifolia (left) and relative taxonomy (right). 


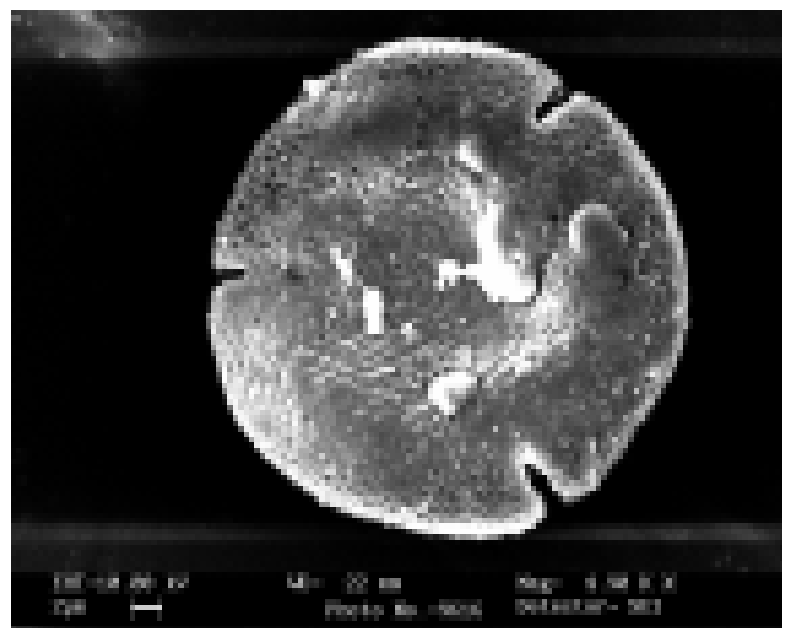

Figure 4. Pollen grain classifiable to the family of Liliacées, perhaps of Fraxinus angustifolia.

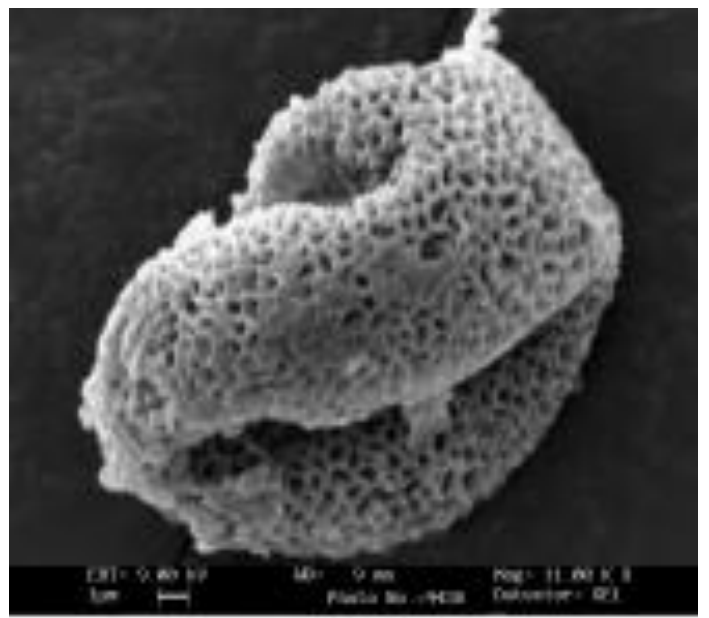

Figure 5. Pollen grain not easy to classify.

\subsection{Flax and cotton fibers Captions/numbering}

The flax fibers are produced by the beams contained in the fibrous layer of the stem of some Liberian herbaceous plants belonging to the family of Linacee. The fibers are obtained by a process of maceration that solubilizes peptic and woody substances that hold them welded together.

The chemical composition of flax fiber differs from that of cotton for the lowest cellulose content and a greater presence of hemicellulose and lignin.

The fibers of flax have a length of $6-50 \mathrm{~mm}$ and a diameter of 6-40 micrometers, pseudo-cylindrical shape, transverse striations, a narrow central channel and nodal thickenings of the walls called kink bands or dislocations, which confer to the fibers a typical form of bamboo, (fig 6).

The observation at high magnification allows to identify some characteristics of the flax fibers, while the EDS has provided the chemical analysis of organic and inorganic impurities surface, in the form of individual particles or crystalline aggregates.

The detailed analysis shows that the deposits present on the fibers are composed in most of the cases of Calcium $(\mathrm{Ca})$, therefore we can suggest to the presence of Calcium Carbonate $\left(\mathrm{CaCO}_{3}\right)$ encrustations, (see Figs. 7 and 8). 


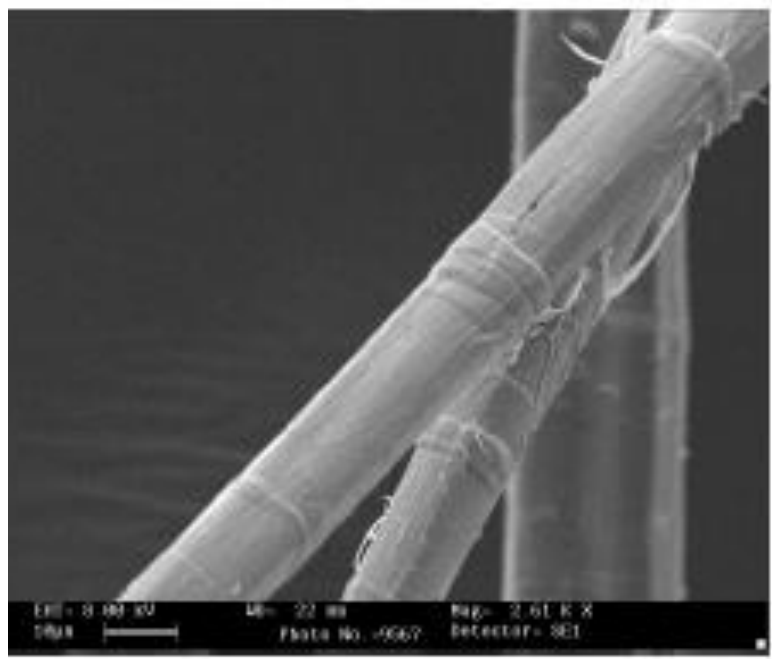

Figure 6. Modern flax fibers without encrustations showing the typical bamboo-structure.

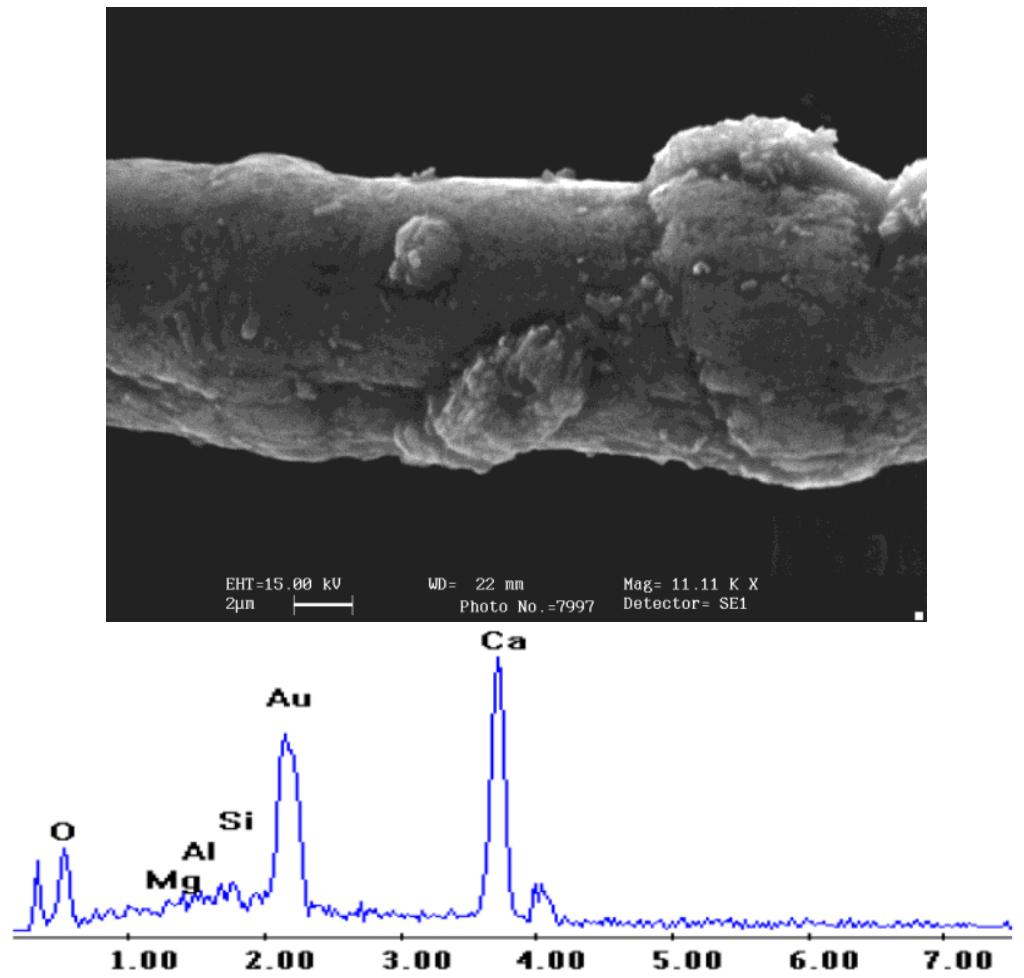

Figure 7. Encrusted flax fiber coming from the TS, with relative spectrum, showing the presence of Ca. 

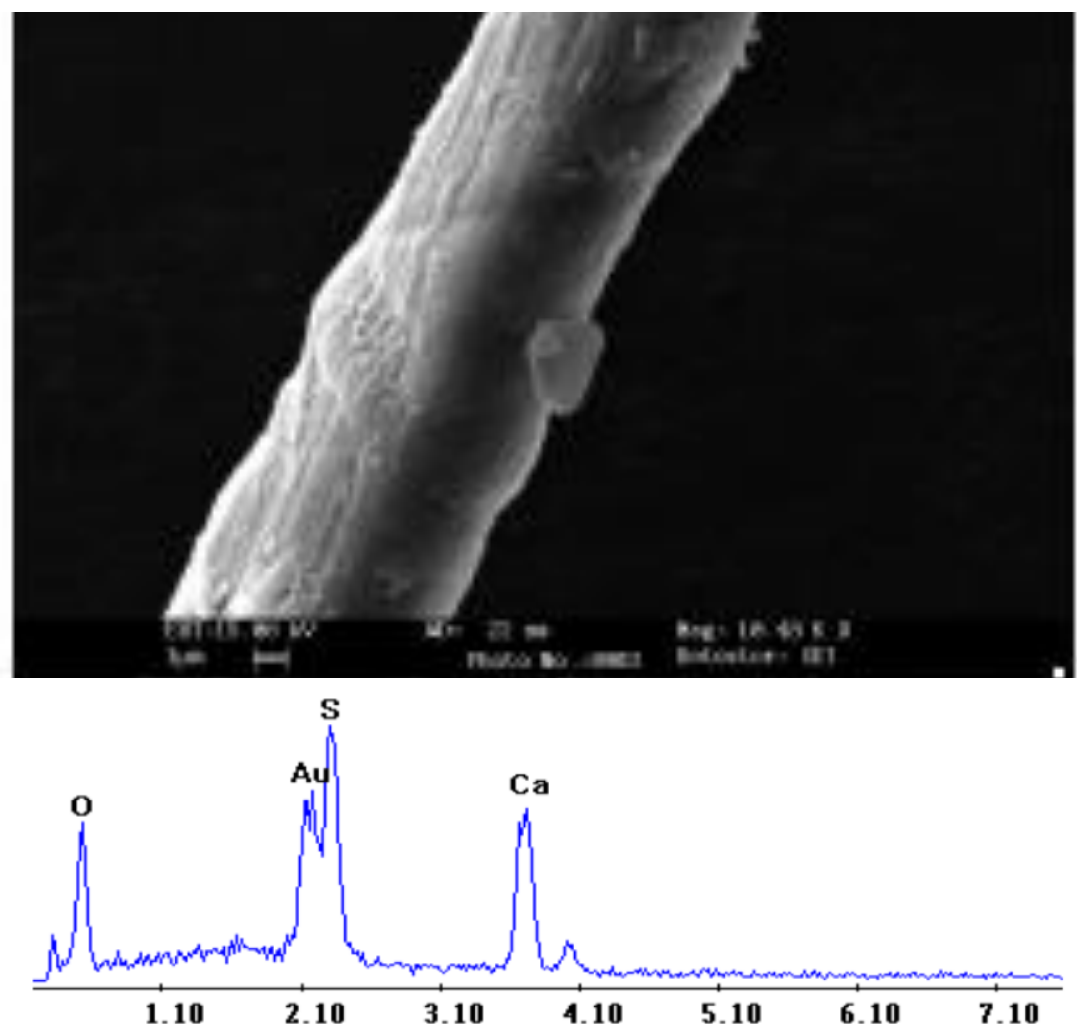

Figure 8. Flax fiber coming from the TS, with relative spectrum, showing the presence of Ca.

Cotton is a vegetable fiber obtained from the genus Gossypium, plants, family Malvaceae; the cotton fibers in the TS are from plants of the species Herbaceum.

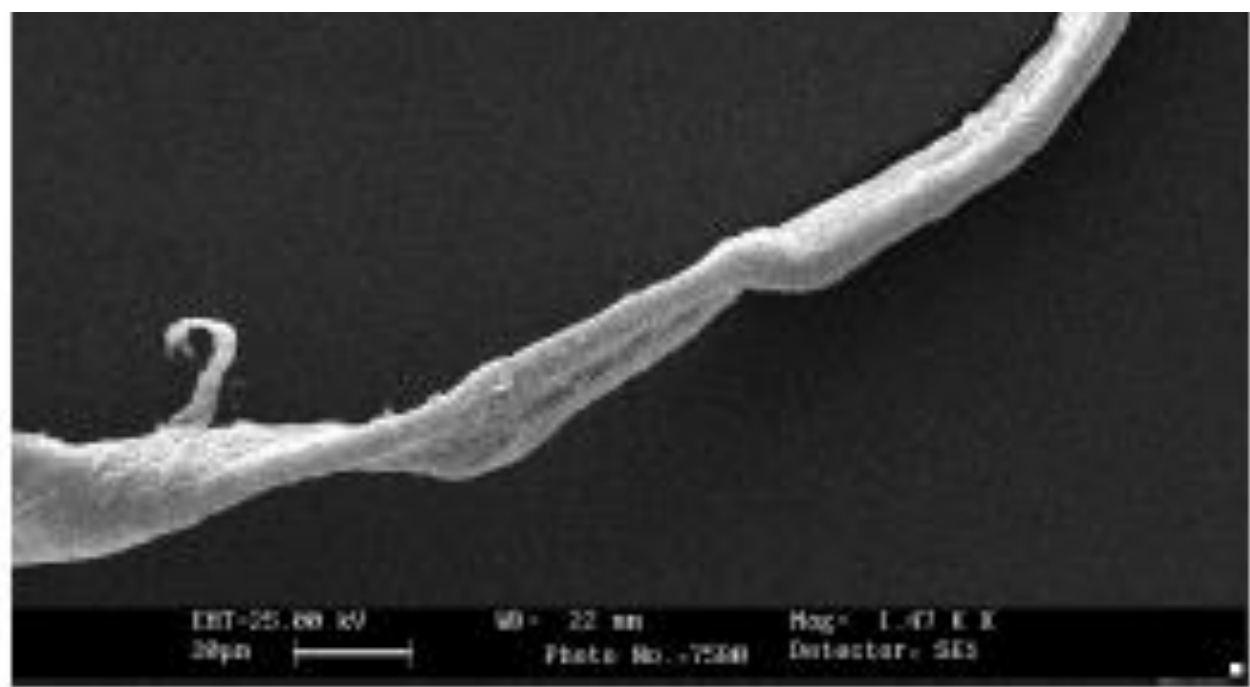

Figure 9. Typical tape structure of a cotton fiber coming from the TS.

A single fiber of cotton, whose length is approximately 2500 times its diameter, is composed of a primary wall, a thicker secondary wall and a central canal, said lumen, which contains the protoplasmic juices. The primary wall, consisting of cellulose $(80 \%)$, hemicellulose and pectin (3\%), 
waxes, fats and proteins (2\%) is covered by a thin cuticle characterized by overlapping layers of laminated nature. Typical morphology of the fibers of cotton, tape twisted, is clearly visible at magnification greater than $100 x$.

Fig. 9 shows typical cotton fiber coming from the TS.

\subsection{Mites, spores and fungi}

In some stubs, especially GI and HI, remains of mites, the Acarina, vulgarly known as mites, (order of arachnids, see Fig. 10) have been found.

Other biological particles have been identified as spores of filamentous fungi belonging to the genus Aspergillus Glaucus, fig 11, and Cladosporium sp. These types of organisms are present in large number in the stubs.

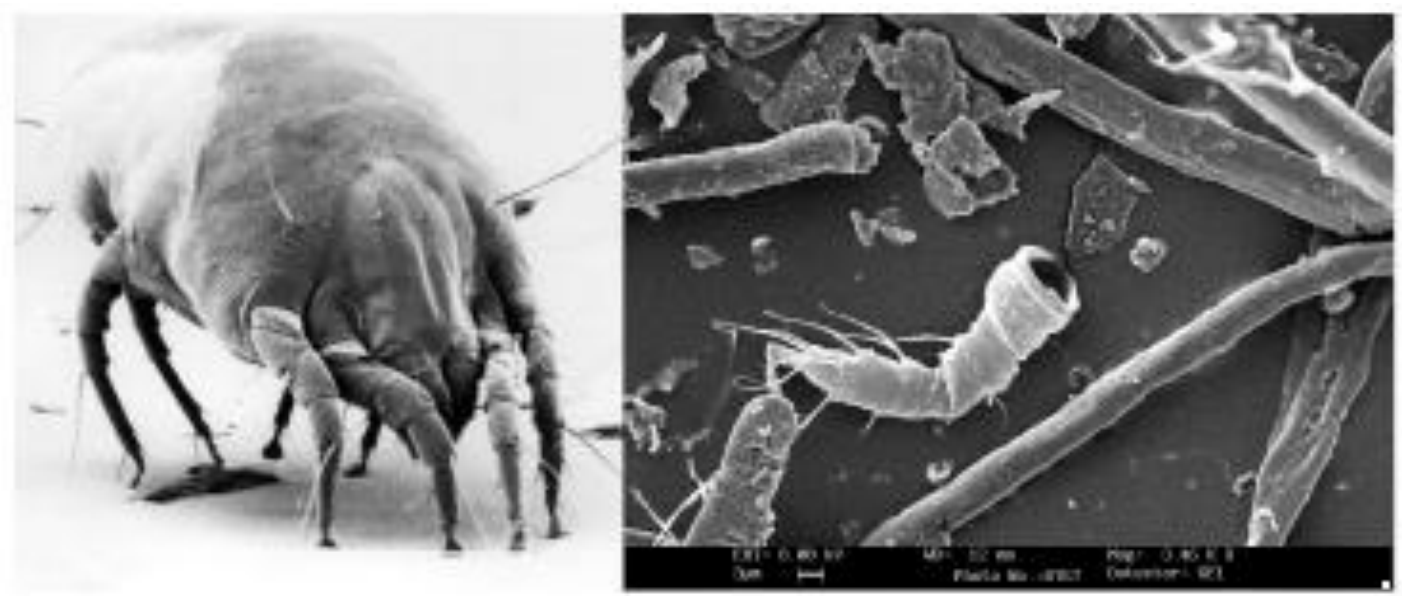

Figure 10. A mite (on the left) and remnants of mites in the TS dust (on the right).
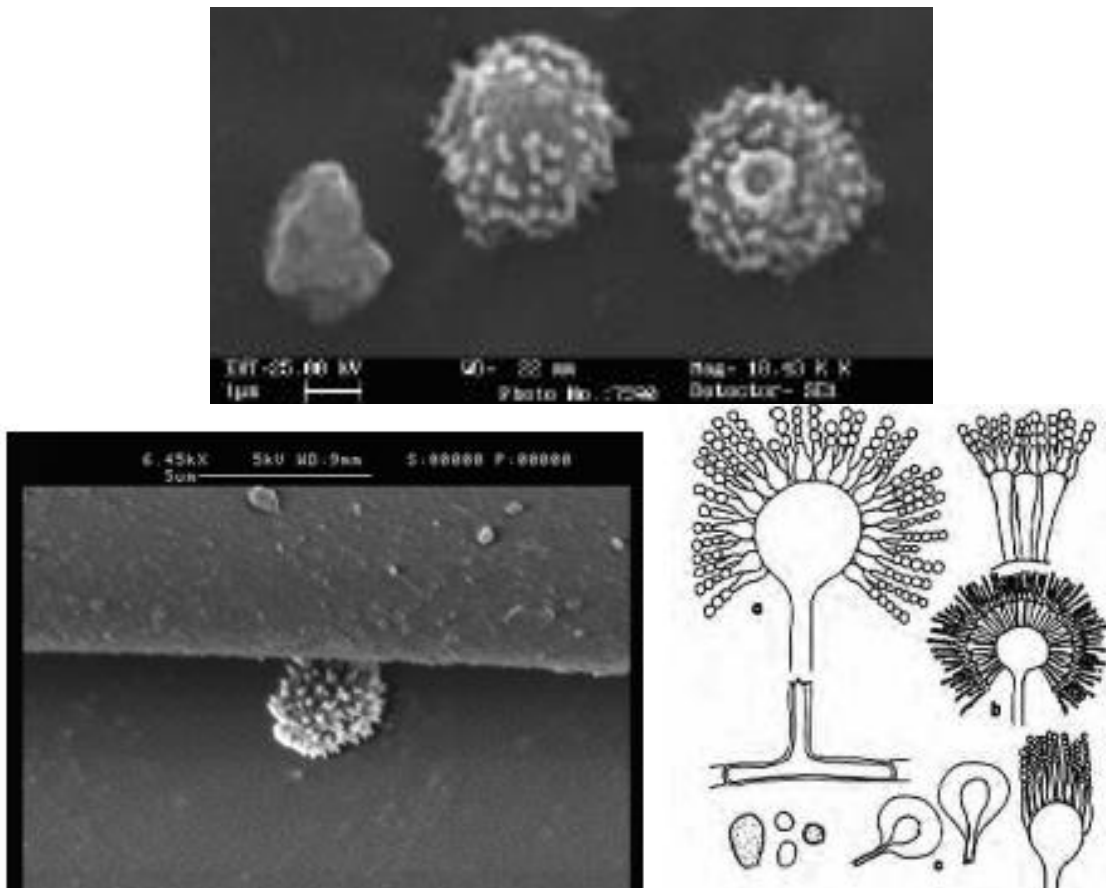

Figure 11. Aspergillus Glaucus of the TS dusts and corresponding morphology. 


\subsection{Mineral particles}

Many mineral particles were found in the TS dusts, with size in the range 3-30 $\mu \mathrm{m}$. They have different colours but prevalently are white or reddish. The attention has been focalized on the reddish particles, also because they are not so common in the soils of northern Italy where the TS is now conserved for centuries.

It was instead found that the Jerusalem soil contains many red particles. Therefore a comparison between the reddish particles coming from a Jerusalem soil sample and the reddish mineral particles coming from the TS is here reported.

Fig. 12 shows a set of white or grey particles coming from a layer of soil just under the S. Sepulcher in Jerusalem and (on the bottom) reddish particles coming from the soil of Mt. Zion in Jerusalem. Two EDS spectra of these reddish particles are reported in Fig. 13.

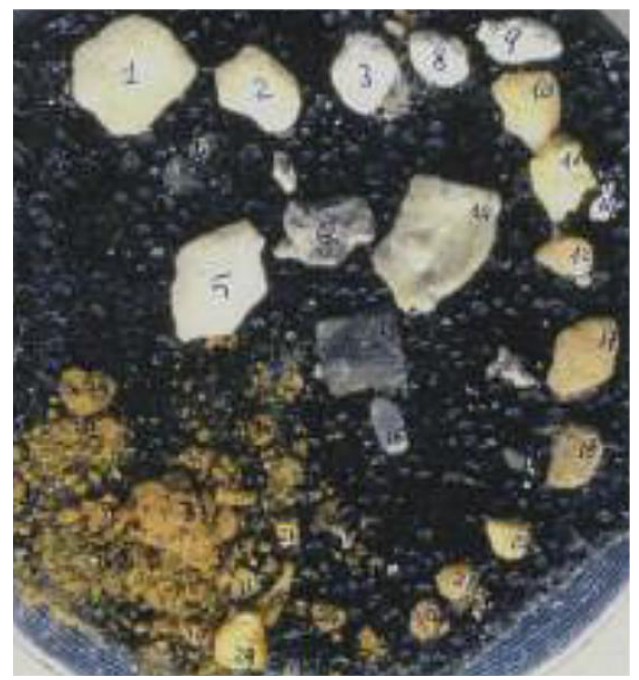

Figure 12. Mineral particles sampled in Jerusalem; the reddish ones (on the bottom) coming from Mt. Zion are those of interest for the present analysis.
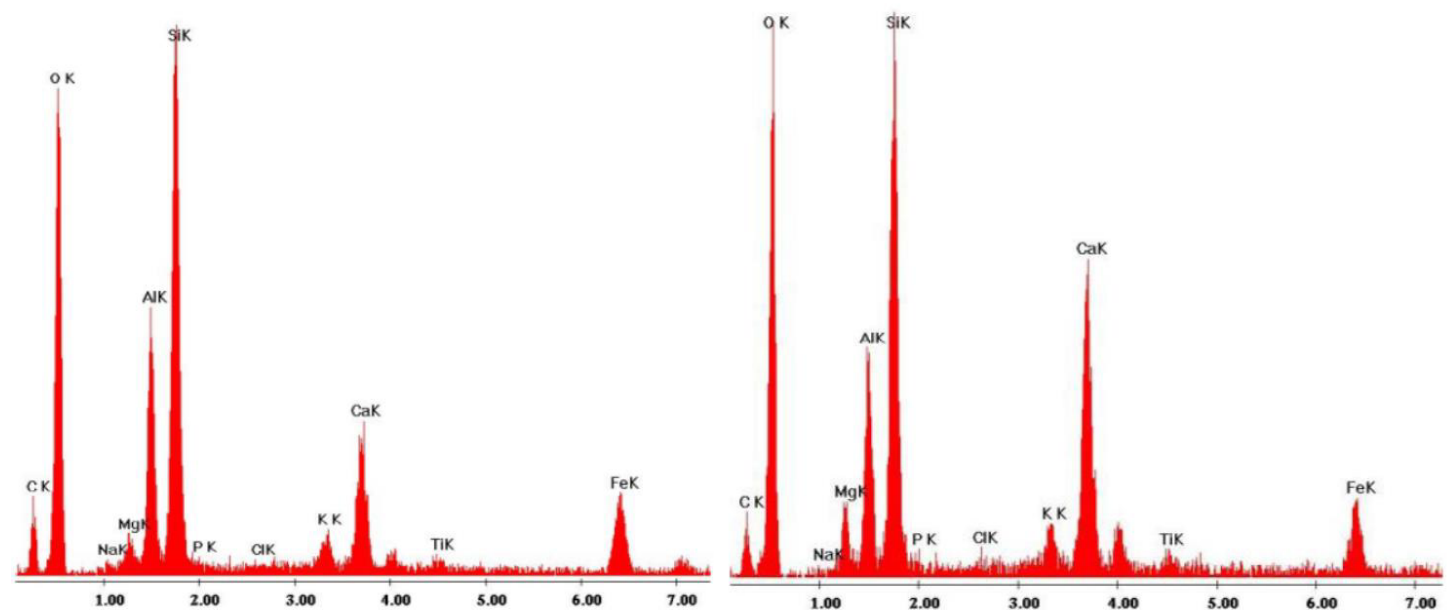

Figure 13. EDS spectra of the reddish mineral particles coming from Mt- Zion of Fig. 12. 


\section{MATEC Web of Conferences}

Fig. 14 reports some dusts coming from the Stub H5 of the TS dusts and the arrow shows the reddish particle tested, whose spectrum is reported in Fig. 15. Fig. 16 reports some dusts coming from the Stub H6 and the arrow shows the reddish particle tested, whose spectrum is reported in Fig. 17.

It appears evident that the spectra of particles taken from Mt. Zion (Fig. 15) are quite similar to those of Stubs H5 and H6 (Fig. 15 and 17). Although more accurate analyses should be necessary for a complete identification, those particles are very similar to the typical local clay of Jerusalem (and of other Mediterranean areas influenced by the winds of the Sahara desert). They seem to belong of the Illite-Smectite family also containing gypsum.

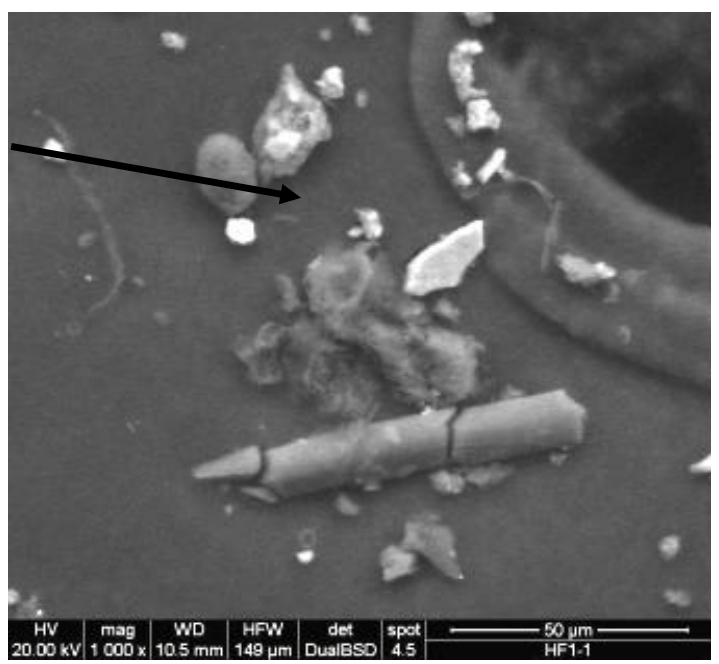

Figure 14. Dust particles of Stub H5: the arrow shows the reddish particle whose spectrum is reported in Fig. 15.

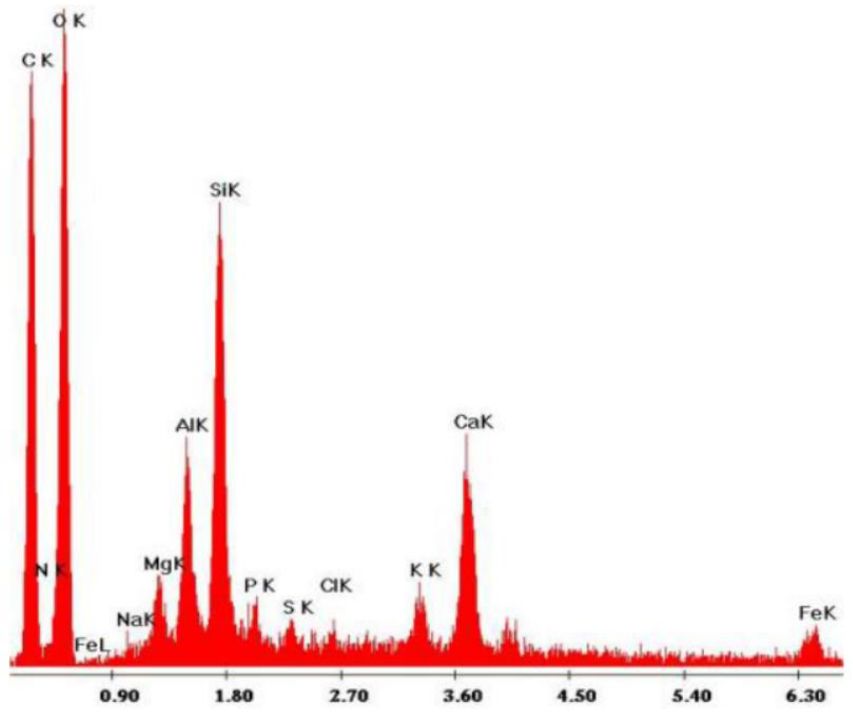

Figure 15. EDS spectrum of the particle shown in Fig. 14. 


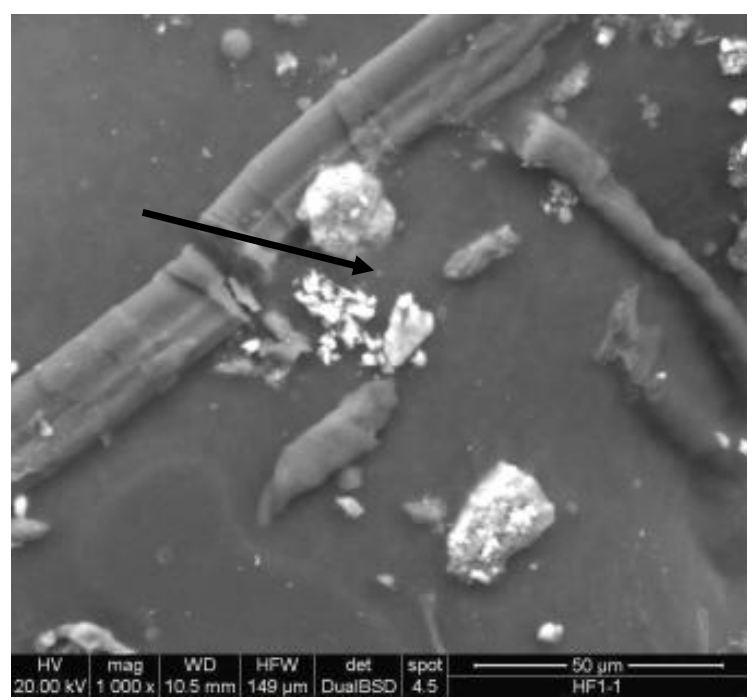

Figure 16. Dust particles of Stub H6: the arrow shows the reddish particle whose spectrum is reported in Fig. 17

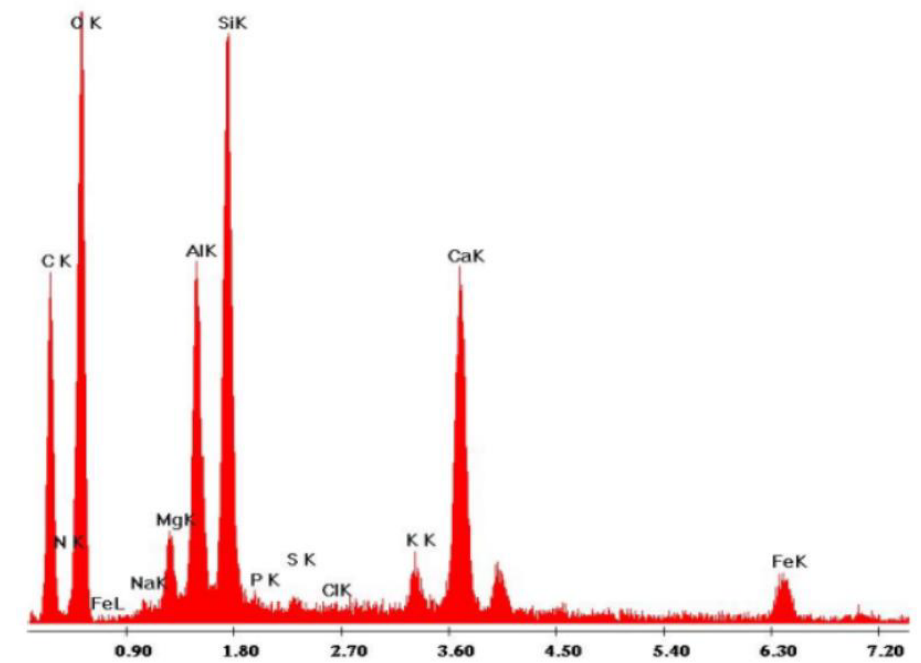

Figure 17. EDS spectrum of the particle shown in Fig. 16.

\subsection{Particles possibly coming from body fluids}

Among the vacuumed dusts, there are some biological particles not easy to be identified. Many red particles of the dusts are of mineral type, see Section 3.4, but there are also few of them looking like biological ones. It is well known [11, 12] that there is human blood on the TS and therefore these few red particles of biological type were tested from a spectral point of view to see if they can be compatible with blood.

According to J. Heller and A. Adler [11] the TS samples of human blood contain various elements such as $\mathrm{Na}, \mathrm{Mg}, \mathrm{Al}, \mathrm{Si}, \mathrm{P}, \mathrm{S}, \mathrm{Cl}, \mathrm{K}, \mathrm{Ca}, \mathrm{Fe}$. The elemental analysis performed by EDS spectroscopy on the red biological particles coming from the vacuumed dusts puts in evidence the presence of $\mathrm{Si}$, $\mathrm{Mg}, \mathrm{Na}, \mathrm{Cl}, \mathrm{Ca}$ and $\mathrm{Fe}$.

These elements are present in blood and body fluids involved in various enzymatic processes and metabolism. The elements of interest in this specific case are:

- Sodium $(\mathrm{Na})$ : it is present in ionic form in blood and in intracellular fluids; 


\section{MATEC Web of Conferences}

- Chlorine (Cl): it is mostly present in ionic form in extracellular fluids;

- Calcium $(\mathrm{Ca})$ : it may reach $1 \%$ in body fluids and it controls the coagulation process;

- Iron (Fe): an adult body contains about $4-5 \mathrm{~g}$ of iron, the $65 \%$ of which is contained in the haemoglobin. About $0.5 \mathrm{~g}$ of iron are contained in one liter of blood. Iron is an essential constituent of hemoglobin and myoglobin.

The red particle of Fig. 18 has been analyzed after metallization. The spectra of Fig. 19 reveal the presence of $\mathrm{Si}, \mathrm{Mg}, \mathrm{Na}, \mathrm{Cl}, \mathrm{Ca}$ and $\mathrm{Fe}$. Given this, it is possible to explain the presence of these elements assuming that the particles under analysis either are of blood or were in contact with blood, but at the same time, it is not true the opposite: the presence these elements does not allow to claim that it is unequivocally blood. Therefore, being the particle under analysis red, of biological type, and containing elements typical of blood, we can deduct that this particle was probably encrusted with blood, but the affirmation is obviously not sure.

As many touched the TS during many centuries, and remembering that various persons restored the TS (the Chambéry nouns spent many hours after the 1532 fire), it seems nevertheless hazardous to think that this possible blood particle came from the TS Man without thinking that the blood in question possibly derived for example from a puncture caused by a needle used during sewing.

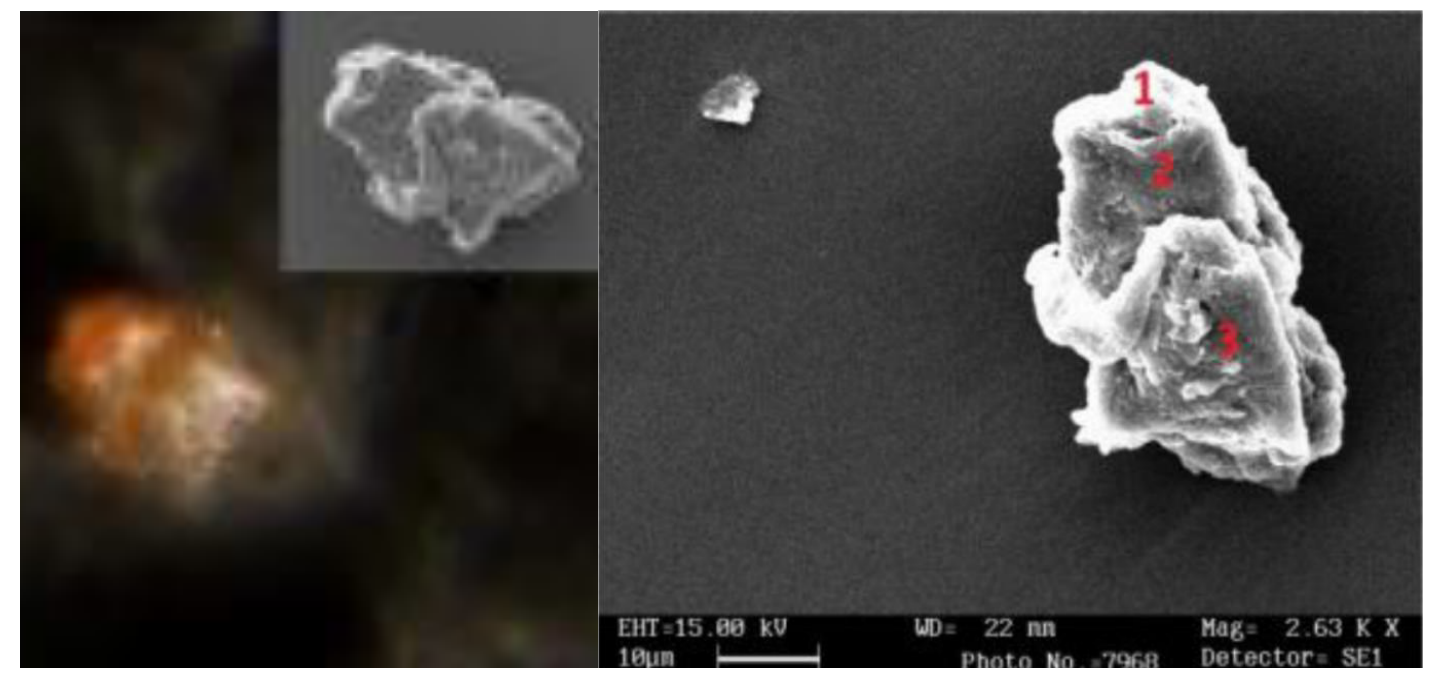

Figure 18. Photomicrograph of the red particle under analysis made at optical microscope (on the left) and the same particle seen at SEM after gold metallization at the center and at the right, with the numbers of the corresponding spectra shown in Fig. 19.

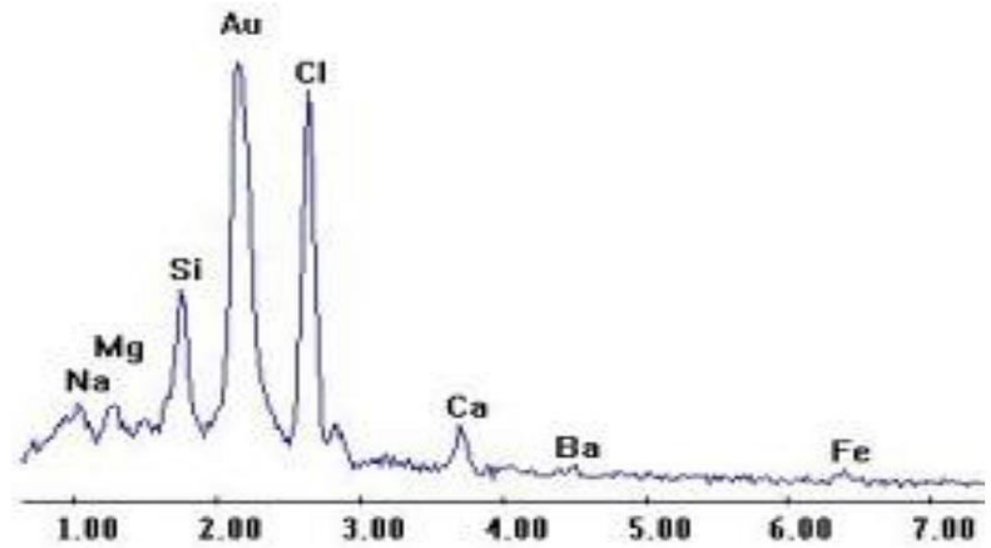

Figure 19. EDS spectra of the red particle of Fig. 18. 


\section{Conclusive remarks}

The Padua University Research Project enabled the analysis of particles in the range from 3 to $30 \mu \mathrm{m}$, vacuumed from the Turin Shroud. They have been studied using optical microscopes, SEM, ESEM and EDS with the aim to classify them and possibly to refer them to the environments where, from historical information, the TS was exposed.

The following particles have been studied and some of them have been classified focalizing the attention to the pollen grains to detect if M. Frei's results can be confirmed or not. In addition it was not neglected the possible detection of new information, possibly useful for the TS studies in general. Although the EDS data are mainly qualitative, due to the beam size, depth of analysis and small amount of the particles, some reasonable conclusions can be deduced on the whole particle chemical composition.

- Pollen grains. The analyzed dusts do not contain the large number of pollen detected by M. Frei $[8,9]$ in his sticky tapes, probably as a consequence of the different sampling method. Mostly, one pollen grain was detected in each stub containing the vacuum dusts from the TS. A pollen grain of Phillyrea Angustifolia was detected, thereby partially confirming M. Frei's results. Also a pollen grain apparently of Fraxinus and one of Cedar of Lebanon have been detected.

- Flax and cotton fibers. Although the majority of the textile fibers composing the TS are of flax, there are also some cotton fibers of Gossypium Herbaceum. Some fibers show the presence of inorganic impurities on their surface; these encrustations seem of calcium carbonate.

- Mites, spores and fungi. Some remnants of mites have been detected in the vacuumed dusts, and this partially explains the Thymol treatment of the TS done in 1988; spores and fungi are very frequent in these dusts and among them the most frequent is Aspergillus Glaucus.

- Mineral particles. There are many red mineral particles in the dusts (red because they contain iron) that are compatible with the Jerusalem soil. They seem to belong to the Illite-Smectite family, also containing gypsum.

- Particles possibly coming from body fluids. A red biological particle was studied and also analyzed via $\mathrm{EDS}$; it contains elements such as $\mathrm{Si}, \mathrm{Mg}, \mathrm{Na}, \mathrm{Cl}, \mathrm{Ca}$ and $\mathrm{Fe}$ that are also present in human blood, but, due to the various kinds of pollution in the centuries, it is not possible to correlate it to the TS Man.

This analysis is obviously not conclusive and many open issues have to be clarified with future studies, also addressed to more specific tests. For example a larger number of dust particles should be used to confirm the results reported in the interesting studies on pollen $[8,9,10]$ and in the comparisons between the mineral particles coming from the TS and the Jerusalem soil. This last study could be an additional clue in the TS research confirming its exposition in the Jerusalem environment.

\section{Acknowledgements}

Work done with the financial support of the University Research Project-Padua, Italy 2008 \#CPDA099244 entitled "Multidisciplinary analysis applied to the Shroud of Turin: A study of body image, of possible environmental pollution and of micro-particles characterizing the flax fabric." The authors wish to thank Giulio Fanti, the principal investigator of the above research project.

\section{References}

1. G. Fanti, et al. (24 authors): "Evidences for Testing Hypotheses about the Body Image Formation of The Turin Shroud", the Third Dallas International Conference on the Shroud of Turin: Dallas, Texas, September 8-11, 2005.

2. G. Fanti, J.A. Botella, F. Crosilla, F. Lattarulo, N. Svensson, R. Schneider, A.D. Whanger "List of Evidences of the Turin Shroud", Int. Workshop on the Scientific Approach to the Acheiropoietos Images, ENEA Research Center of Frascati (Italy), 4-5-6 May 2010.

3. G. Fanti: "La Sindone, una sfida alla scienza moderna", Aracne editrice, March 2008. 


\section{MATEC Web of Conferences}

4. G. Fanti, "Hypotheses regarding the formation of the body image on the Turin Shroud. A critical compendium”, J. of Imaging Sci. Technol., Vol. 55, No. 6, p. 060507 (Dec 22 2011).

5. Fanti G., "Can a Corona Discharge Explain the Body Image of the Turin Shroud?", Journal of Imaging Science and Technology, Vol. 54, No. 2, March/April 2010, p. 020508-1/10.

6. P. E. Damon et al. 24 authors, "Radiocarbon dating of the Shroud of Turin", Nature, Vol. 337, February 16, 1989, pp. 611-615.

7. M. Riani, A. C. Atkinson, G. Fanti, F. Crosilla "Regression Analysis with Partially Labelled Regressors: carbon dating of the Shroud of Turin", Statistics and Computing Journal, 2013.

8. M. Frei, "Il passato della Sindone alla luce della palinologia", in La Sindone e la Scienza, II Congresso Internazionale di Sindonologia, Bologna 27-29 Novembre 1981.

9. M. Frei, "Identificazione e classificazione dei nuovi pollini della Sindone", in La Sindone Scienza e Fede (a cura di L. Coppini e F. Cavazzuti), Ed Cleub, Bologna, 1983.

10. A. Danin et al., "Flora of the Shroud of Turin", Missouri Botanical Garden Press, St. Louis, Missouri (1999).

11. J. H. Heller A. D. Adler, "Blood on the Shroud of Turin", Applied Optics, 19(16), pp. 2742-2744, (1980).

12. P.L. Baima Bollone, "Indagini identificative su fili della Sindone", Giornale della Accademia di Medicina di Torino, n. 1-12, 1982, pp. 228-239.

13. G. Fanti, R. Basso, " Statistical Analysis Of Dusts Taken From Different Areas Of The Turin Shroud", Proc. of Shroud Science Group International Conference The Shroud Of Turin: Perspectives on A Multifaceted Enigma, Ohio State University, August 14-17, 2008, Libreria Progetto, Padova, Italy 2009.

14. G. Riggi Di Numana, "Rapporto Sindone” 1978/1987, 3M Edizioni, Milano 1988.

15. M. Flury-Lemberg, "Stato e problemi di conservazione della Sindone di Torino", AA. VV., "Sindone - 100 anni di ricerca", Istituto Poligrafico e Zecca dello Stato, 1998, pp. 255-267.

16. A. D. Adler, "The Shroud fabric and the body image: chemical and physical characteristics", in: "The Turin Shroud, past, present and future", Proceedings of the International Scientific Symposium, Torino, 2-5 March 2000, Effatà Editrice, Cantalupa (TO) 2000, pp. 51-73. 